\title{
BACTERIOLOGICAL AND IMMUNOLOGICAL STUDIES IN FAMILIES WITH PNEUMOCOCCIC INFECTIONS : THE DEVELOPMENT OF TYPE-SPECIFIC ANTIBODIES IN HEALTHY CONTACT CARRIERS 1, 2
}

\author{
By MAXWELL FINLAND AND R. CARMICHAEL TILGHMAN \\ (From the Thorndike Memorial Laboratory, Second and Fourth Medical Services (Harvard), \\ Boston City Hospital and the Department of Medicine, Harvard Medical School, Boston)
}

(Received for publication May 18, 1936)

The occurrence of multiple cases of pneumonia due to the same type of pneumococcus within a family or among persons in contact with cases and the presence of milder respiratory tract infections associated with the same organism among the contacts of pneumonia cases were recorded in the previous paper (1). These observations, coupled with the high incidence of healthy carriers of the same type of pneumococcus among family contacts of persons ill with pneumonia, suggested an opportunity for studying the immune response to the milder infections with these disease-producing pneumococci as well as the response to their presence in the pharynx when they do not give rise to clinical symptoms. In this paper are presented the results of more detailed bacteriological and serological studies in the patients and other members of the household of 5 of the 33 families previously reported (1) in which multiple cases of pneumococcic infection occurred.

\section{MATERIAL AND METHODS}

Bacteriological studies were directed mainly to the isolation and serological identification of pneumococci. Sputum, blood, pleural fluid, discharges from the ear, and pharyngeal swabs were obtained from cases and cultured (2). Pharyngeal swabs from healthy contacts or from patients who raised no sputum were placed into rabbits' blood broth, incubated for a few hours, and the resulting growth inoculated into mice. These blood broth cultures, the peritoneal exudate of the mouse at various intervals, and the mouse heart's blood were streaked on the surface of blood agar plates, and numerous suspicious colonies picked, isolated in pure culture, and identified

1 This study was aided, in part, by a grant given in honor of Francis Weld Peabody by the Ella Sachs Plotz Foundation.

2 This work was carried out with the technical assistance of Mrs. Mildred W. Barnes. by morphological and cultural characteristics, by bile solubility, and by agglutination with antipneumococcic sera for Types I-XXXII (Cooper).

Immunological studies consist of tests for type-specific agglutinins and mouse protective antibodies in the blood serum. The protection tests were carried out only with the types for which cultures of maximal virulence were available. Attempts to raise the virulence of a Type XXII culture by repeated mouse passage were not successful, the lethal dose remaining less than $0.000,001$ cc. Tests for agglutinins were carried out with formalized suspensions of pneumococci. When floccular agglutination could not be demonstrated, stained smears of fresh 12-hour blood broth cultures mixed with the test serums were examined for the presence of microscopic agglutination.

While it was hoped to obtain early and frequent cultures and bloods from all contacts, this was possible only in some of the members of one of the families studied. Single cultures and serum samples were obtained in the others.

\section{CLINICAL, BACTERIOLOGICAL, AND SEROLOGICAL} OBSERVATIONS

Family McD. (Table I) had two members admitted to the hospital, both of whom had lobar pneumonia followed by empyema due to a pneumococcus Type I. The first manifestation of infection in family McD., however, was in the mother who contracted a mild irritative cough in November. She was asymptomatic aside from the cough which persisted almost unchanged for $2 \frac{1}{2}$ months, that is until the middle of January. The eldest daughter, Ma., age 8 years, developed an upper respiratory tract infection on December 31, with fever, cough, and malaise. Ma. was not ill enough to go to bed but continued her usual routine and was well after a three day illness. On January 4 both $C$. and T. showed evidence of a cold, and on January 8 and 9, respectively, they had identical symptoms indicative of a more severe infection, namely vomiting, fever, prostration, and epigastric pain. They were subsequently admitted to The Boston City Hospital with lobar pneumonia and later had empyema. Type I pneumococci were isolated from the pleural fluid of both C. and T. Throughout the period of respiratory infections in the family, the father remained quite well. Throat cultures were made on Februarv 3 on the father. 
TABLE I *

Family McD. (Number 13)

\begin{tabular}{|c|c|c|c|c|c|c|c|c|c|c|c|c|}
\hline \multirow{3}{*}{$\begin{array}{c}\text { Pa- } \\
\text { tient }\end{array}$} & \multirow{3}{*}{ Age } & \multirow{3}{*}{$\begin{array}{c}\text { Relation- } \\
\text { ship }\end{array}$} & \multirow{3}{*}{ Clinical } & \multicolumn{3}{|c|}{ Bacteriology } & \multicolumn{6}{|c|}{ Immunology } \\
\hline & & & & \multirow{2}{*}{ Date } & \multirow{2}{*}{ Throat swab } & \multirow{2}{*}{ Other } & \multicolumn{4}{|c|}{ Agglutinins } & \multicolumn{2}{|c|}{ Protection } \\
\hline & & & & & & & Date & I & XI & $\operatorname{xxIV}$ & I & $\mathbf{v}$ \\
\hline Th. & $\begin{array}{c}\text { years } \\
46\end{array}$ & Father & Well & Feb. 3 & XI, XXIV & & Feb. 3 & 0 & + & + & 0 & 0 \\
\hline Mo. & 35 & Mother & Nov. 25 , cough for 10 weeks & Feb. 3 & I & & Feb. 3 & 0 & $\mathbf{0}$ & 0 & 500 & $\mathbf{0}$ \\
\hline Ma. & 8 & Daughter & Dec. 31 , fever, cough, 3 days & Feb. 3 & I & & Feb. 3 & 0 & 0 & $\mathbf{0}$ & 5000 & $\mathbf{0}$ \\
\hline C. & 6 & Daughter & Jan. 8, lobar pneumonia, empyema & Jan. 15 & & P.F. $=I$ & & & & & & \\
\hline T. & 4 & Daughter & Jan. 9 , lobar pneumonia, empyema & Jan. 16 & & P.F. $=I$ & & & & & & \\
\hline
\end{tabular}

* Explanation of Tables I to IV

Number after family designation corresponds to group number in Table I of previous paper (1). Clinical: dates refer to onset of symptoms. Bacteriology: Roman numerals represent pneumococcus types; P.F. = pleural fluid; S.V. = Streptococcus viridans, S.H. = Streptococcus hemolyticus. Immunology: Date represents withdrawal of blood for serology; agglutinins: $+=$ microscopic agglutination present but negative macroscopically; $1: 2,1: 4$, etc. $=$ greatest dilution showing floccular agglutination; protection = mouse protective antibodies in lethal doses per cc.; $-\stackrel{=\text { not }}{-}$ done.

mother, and daughter Ma., at which time venous blood was drawn for immunological studies. The data obtained are shown in Table I. Both the mother and daughter Ma., who had had mild respiratory infections, were found to be carriers of a Type I pneumococcus while the father who had had no clinical evidence of infection did not harbor a Type I pneumococcus in his throat but carried pneumococci Types XI and XXIV. The father's serum showed microscopic agglutination against pneumucocci Types XI and XXIV but not against Type I. The blood of the mother and daughter Ma. had no demonstrable agglutinins, either microscopically or macroscopically, against pneumococci Types I, XI and XXIV. The father's serum showed no protective antibody against pneumococcus Type I while protection against this type was demonstrated in the blood serum of both the mother and the daughter, Ma. Control protection tests against pneumococcus Type $\mathrm{V}$ were negative in these 3 individuals.

Summary. Family McD. consisted of five members, two of whom had a pneumococcus Type I empyema, two of whom had upper respiratory infections and were carriers of pneumococcus Type I, and one of whom remained well and did not carry a Type I pneumococcus. Protection against pneumococcus Type I was demonstrated in the blood serums of the carriers of Type I but not in the blood of the father who was not a Type I carrier.

TABLE II

Family L. (Number 16)

\begin{tabular}{|c|c|c|c|c|c|c|c|c|c|c|c|c|c|c|}
\hline \multirow{3}{*}{ Patient } & \multirow{3}{*}{ Age } & \multirow{3}{*}{$\underset{\text { tionship }}{\text { Rela- }}$} & \multirow{3}{*}{ Clinical } & \multicolumn{4}{|c|}{ Bacteriology } & \multicolumn{7}{|c|}{ Immunology } \\
\hline & & & & \multirow{2}{*}{ Date } & \multirow{2}{*}{$\begin{array}{l}\text { Spu- } \\
\text { tum }\end{array}$} & \multirow{2}{*}{$\begin{array}{l}\text { Throat } \\
\text { swab }\end{array}$} & \multirow{2}{*}{ Blood } & \multirow{2}{*}{ Date } & \multicolumn{5}{|c|}{ Agglutinins } & \multirow{2}{*}{$\begin{array}{c}\text { Protec- } \\
\text { tion }\end{array}$} \\
\hline & & & & & & & & & II & III & $\mathbf{x}$ & $\mathbf{x I X}$ & $\mathbf{X X I}$ & \\
\hline S. L. & $\begin{array}{c}\text { years } \\
18\end{array}$ & Son & $\begin{array}{l}\text { Feb. } 1 \text {, lobar pneumonia, se- } \\
\text { rum therapy }\end{array}$ & Feb. 3 & II & & 0 & $\begin{array}{l}\text { Feb. } 3 \\
\text { Feb. } 4\end{array}$ & $\begin{array}{l}0 \\
1: 32\end{array}$ & & & & & \\
\hline N.L. & 13 & Son & Feb. 11, lobar pneumonia & Feb. 12 & II & & & Mar. 1 & $1: 16$ & $\mathbf{0}$ & 0 & 0 & $\mathbf{0}$ & 50,000 \\
\hline F. L. & 50 & Father & Well & Mar. 1 & & $\mathrm{X}, \mathrm{XXI}$ & & Mar. 1 & 0 & 0 & 0 & 0 & 0 & 0 \\
\hline M. L. & 45 & Mother & Well & Mar. 1 & & ${ }_{\text {XIX }}^{\text {III, }}$ & & Mar. 1 & $1: 2$ & 0 & 0 & 0 & 0 & 5,000 \\
\hline
\end{tabular}


Family $L$. Table II gives the data regarding this family in which two brothers were ill of lobar pneumonia. S., without preceding infection of the upper respiratory tract, suddenly on February 1 had the classical symptoms of a lobar pneumonia and was admitted on February 3 to The Boston City Hospital with physical signs and $x$-ray evidence of involvement of the left lower lobe. Because of the finding of a pneumococcus Type II in his sputum, he was treated with specific antipneumococcus serum and made a rapid, uneventful recovery. On February 5, N., the brother, who slept in the same bed with S., developed malaise, coryza, and dizziness. N. became worse on February 11, ten days after the onset of the pneumonia in S., with chest pain, temperature of $103^{\circ} \mathrm{F}$., "rusty" sputum, and a diagnosis of pneumonia of the right upper lobe was made by one of the district physicians of the Boston Dispensary. From N.'s sputum a pneumococcus Type II was isolated (1). N. made an uncomplicated recovery. Throat cultures were made on the father and mother on March 1, which failed to yield pneumococcus Type II, but did show pneumococci of other types. Also, on March 1 blood was obtained from N., from the father, and from the mother. It is seen in Table II that $\mathrm{N}$. had agglutinins in a titer of $1: 16$ against pneumococcus Type II and possessed mouse protective antibodies in high titer against this organism. N. had no agglutinins for the types of pneumococci isolated from his mother and father. The father had no demonstrable agglutinins against his own organisms or against the pneumococci from the mother and sons. Likewise the father's blood serum contained no mouse protective antibodies for pneumococcus Type II. In the mother's blood serum agglutinins in low titer and mouse protective antibodies were present against pneumococcus Type II but agglutinins could not be demonstrated for the pneumococci isolated from her and her husband.

Summary. Two brothers of Family L. had Type II pneumococcus pneumonia. Neither the father nor the mother was shown to be a carrier of Type II pneumococcus but each carried pneumococci of different types. The mother possessed agglutinins and protective antibody against pneumococcus Type II but not against her own mouth organisms. The blood serum of the father contained no demonstrable antibodies for any of the pneumococci isolated.

Family D. (Table III) presents an instance of the development of lobar pneumonia, due to pneumococcus Type II, in fou: members of a household within a period of three days. All those ill of pneumonia had had preceding upper respiratory tract infections. All were admitted to The Boston City Hospital and all recovered without postpneumonic complications. Two, the father and the son, were treated with specific antipneumococcic serum. The mother and three other children, as shown in Table III, either remained well or suffered mild colds

TABLE III

Family D. (Number 17)

\begin{tabular}{|c|c|c|c|c|c|c|c|c|c|c|c|c|c|}
\hline \multirow{3}{*}{ Patient } & \multirow{3}{*}{ Age } & \multirow{3}{*}{$\begin{array}{l}\text { Relation- } \\
\text { ship }\end{array}$} & \multirow{3}{*}{ Clinical } & \multicolumn{4}{|c|}{ Bacteriology } & \multicolumn{6}{|c|}{ Immunology } \\
\hline & & & & \multirow{2}{*}{ Date } & \multirow{2}{*}{$\begin{array}{l}\text { Spu- } \\
\text { tum }\end{array}$} & \multirow{2}{*}{$\begin{array}{l}\text { Throat } \\
\text { swab }\end{array}$} & \multirow{2}{*}{ Blood } & \multirow{2}{*}{ Date } & \multicolumn{3}{|c|}{ Agglutinins } & \multicolumn{2}{|c|}{ Protection } \\
\hline & & & & & & & & & $\mathbf{I}$ & II & XXVII & $\mathbf{I}$ & II \\
\hline J. & $\begin{array}{c}\text { years } \\
15\end{array}$ & Son & $\begin{array}{l}\text { Dec. } 25 \text {, lobar pneumonia, } \\
\text { serum therapy }\end{array}$ & $\begin{array}{l}\text { Dec. } 28 \\
\text { Jan. } 7\end{array}$ & $\begin{array}{l}\text { II } \\
\text { II }\end{array}$ & & & $\begin{array}{l}\text { Dec. } 28 \\
\text { Dec. } 29 \\
\text { Jan. } 6\end{array}$ & & $\begin{array}{c}0 \\
1: 32 \\
1: 8\end{array}$ & $\begin{array}{l}0 \\
0\end{array}$ & & \\
\hline M. & 13 & Daughter & Dec. 25, lobar pneumonia & Dec. 29 & & II & & Jan. 6 & & $1: 64$ & & & \\
\hline P. & 48 & Father & $\begin{array}{l}\text { Dec. } 26 \text {, lobar pneumonia, } \\
\text { serum therapy }\end{array}$ & Dec. 29 & II & & II & $\begin{array}{lr}\text { Dec. } & 29 \\
\text { Dec. } 30 \\
\text { Dec. } 31 \\
\text { Jan. } 6 \\
\text { Jan. } 13\end{array}$ & & $\begin{array}{c}0 \\
1: 32 \\
1: 64 \\
1: 16\end{array}$ & $\begin{array}{l}\mathbf{0} \\
0 \\
0 \\
0\end{array}$ & & \\
\hline $\mathbf{R}$. & ? & Mother & Well & Jan. 1 & & S.V. & & & & & & & \\
\hline W. & 10 & Son & Dec. 26 , cough, 2 days & Jan. 1 & & XXVII & & Jan. 9 & 0 & 0 & 0 & 0 & 0 \\
\hline P., Jr. & 9 & Son & Dec 31 , cough, 1 day & Jan. 1 & & II & & Jan. 9 & 0 & + & 0 & 0 & 50,000 \\
\hline Ma. & 7 & Daughter & Well & Jan. 1 & & II & & Jan. 9 & 0 & $1: 8$ & 0 & 0 & 50,000 \\
\hline
\end{tabular}


of short duration. When throat cultures were made on the four members of the family who did not contract pneumonia it was found that two of the children were carriers of a pneumococcus Type II. The mother's throat flora showed no pneumococci, and the remaining child harbored a pneumococcus Type XXVII. It was not possible to obtain blood for immunological study from the mother. The two children, P., Jr., and Ma., who were carriers of pneumococcus Type II, had in their blood serum specific agglutinins and mouse protective antibodies for pneumococcus Type II but did not possess agglutinins against Type XXVII or Type I. The boy, W., from whose throat culture a pneumococcus Type XXVII was isolated, had no agglutinins against his own type pneumococcus, nor did he have agglutinins or protective antibodies for pneumococcus Type II.

Summary. Within a period of three days, four members of Family D. developed lobar pneumonia due to pneumococcus Type II. Two members of the family who did not have the disease were carriers of pneumococcus Type II and both possessed in their blood serum specific antibodies against pneumococcus Type II. A third member, who had only a mild cold, carried a pneumococcus Type XXVII but did not have antibodies against his own mouth organism or against pneumococcus Type II.

Family $P$ is a large one in which bacteriological and immunological studies were conducted on its thirteen members. Eight individuals were admitted to The Boston City Hospital. The first one to become ill was B., who, on February 18, contracted a cough and coryza and on February 21 was admitted to the hospital. His admission temperature of $100^{\circ} \mathrm{F}$. promptly fell to normal and remained normal for the following thirty-six hours, with corresponding subjective improvement. Suddenly on February 23 he was seized with vomiting, had a shaking chill, and pain in the back. His temperature rose to $102.2^{\circ}$, leukocyte count to 21,000 , and later he raised bloody sputum. A pneumococcus Type $\mathrm{V}$ was found in the sputum, and he received specific antipneumococcic serum therapy. The physical signs in the chest and $\mathrm{x}$-ray demonstrated involvement of the right middle lobe. Since the possibility suggested itself that $B$. might have contracted his pneumonia after admission to the hospital, an attempt was made to trace the source of his infection. On the ward, B. had been exposed to three patients with respiratory disease and on these three patients bacteriological and immunological observations were made. One had lobar pneumonia and from his sputum a pneumococcus Type IX was isolated; his blood serum was negative for agglutinins and protective antibodies for pneumococcus Type $\mathrm{V}$, and pneumococcus Type IX agglutinins were also absent. The second contact was admitted because of cardiac failure, bronchitis, and bronchial asthma; his sputum yielded no pneumococci and his blood serum contained no agglutinins or protection against pneumococcus Type V. The third contact had lobar pneumonia due to pneumococcus Type II, which was isolated from the sputum; his blood serum on 2 occasions showed agglutinins against Type II pneumococcus in a titer of $1: 64$ and against Type $\mathrm{V}$ in a titer of $1: 8$, and protection against pneumococcus Type $V$ for 500,000 lethal doses per cc. The immunological data of this third contact suggested him as a possible source for the spread of the Type $\mathrm{V}$ pneumococcus but since no Type $\mathrm{V}$ pneumococci were obtained from his sputum, and also because cross-immunity may occasionally develop (3) with the related Types II and V pneumococci, the conclusion that this third contact was the disseminator of pneumococcus Type $\mathrm{V}$ cannot be drawn with any. degree of certainty.

In Family P. the father, Pe., was the second member to become ill. He had coryza, aching, and felt feverish on February 20. On February 22 and again on February 25 he visited his son $B$. on the ward where no special isolation precautions were observed. During the night of February 25 he was stricken with a chill, had pain in the back, and later produced blood-flecked sputum. The following day he entered the hospital. A pneumococcus Type $\mathrm{V}$ was obtained from his sputum and specific serum therapy was administered. There was consolidation of the right lower lobe. His convalescence was rapid and uncomplicated.

With the appearance of two cases of a Type $V$ pneumococcus pneumonia in father and son with their acute onset separated by an interval of two days, studies were begun on the remaining members of the family. The several members of this family, excepting the youngest one, frequently visited with each other at the hospital. Some of the studies were made during such visits and others were made in the home. Unfortunately, the family did not always cooperate fully, so that our studies are lacking in completeness.

The results of the observations in this family are given in Table IV. G., the five year old daughter, on March 1 , had no pneumococci in her throat culture but, on March 14, pneumococcus Type $\mathrm{V}$ was isolated. On March 18 , G. developed hoarseness and cough, and became suddenly worse on March 24 with fever, malaise, nausea, and anorexia. Consolidation of the entire left lung was diagnosed by physical signs. Her throat swabs of March 25 and 27 and of April 16 yielded pneumococcus Type XXII. Immunological studies of G.'s blood serum of March 25 and 29 showed protection against pneumococcus Type $\mathrm{V}$ but agglutinins for pneumococci Types $\mathrm{V}$ and XXII could not be demonstrated.

D. P., age 6 years, was well until March 28. On March 14 a pneumococcus Type $\mathrm{V}$ was cultured from her pharynx. She suddenly became ill on March 28 and was admitted to The Boston City Hospital on the same day. Again a pneumococcus Type $\mathrm{V}$ was isolated from her throat. There were physical signs of a diffuse bronchitis with probably a bronchopneumonia and for 
TABLE IV

Family $P$. (Number 20)

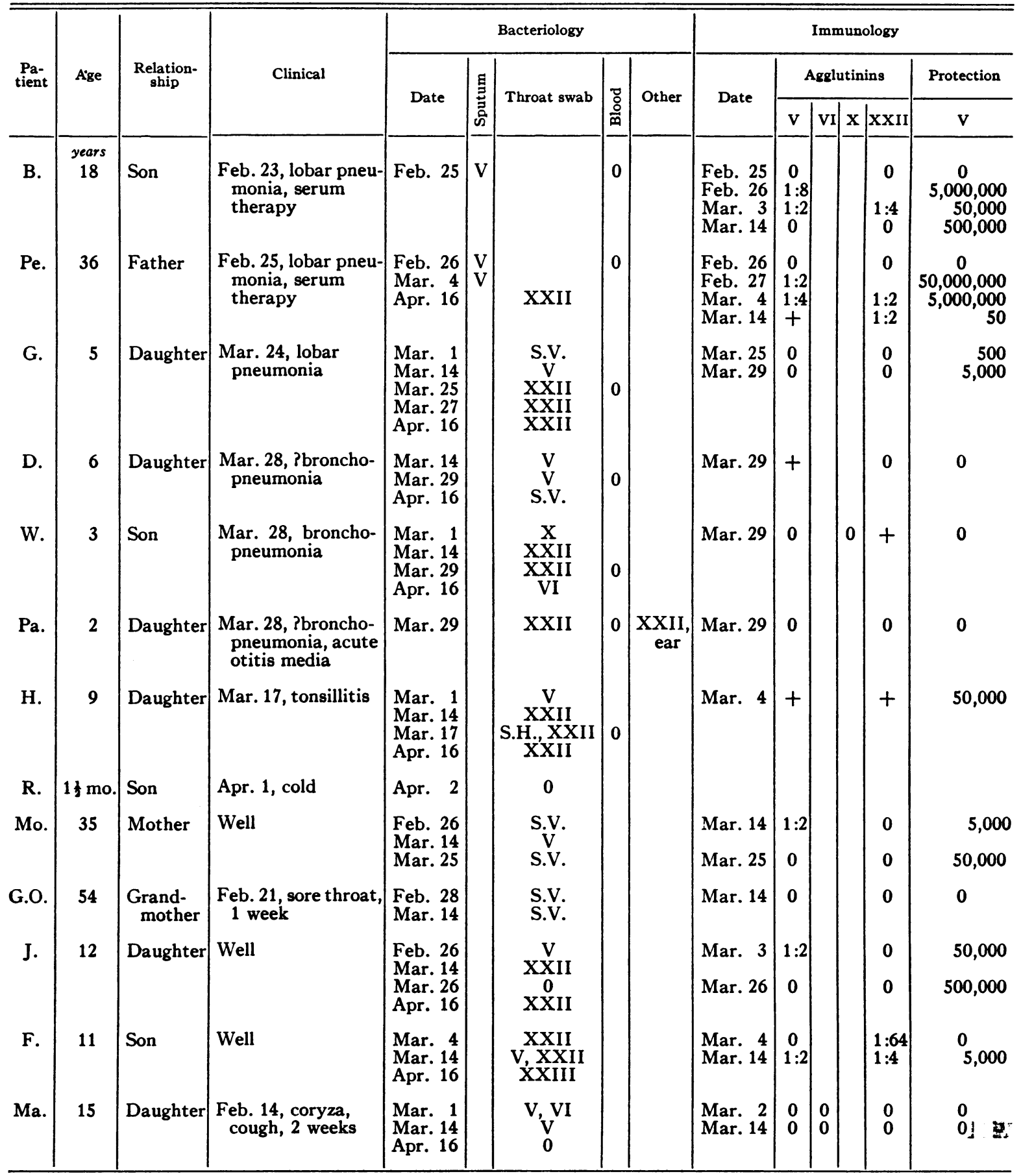

three days she ran an irregular fever between $101^{\circ}$ and $104^{\circ}$. D's. blood serum of March 29 possessed microscopically demonstrable agglutinins and also had mouse protective antibodies against pneumococcus Type $\mathrm{V}$ but no agglutinins for Type XXII pneumococcus. A later throat culture on April 16 showed no pneumococci. W. P., age 3 years, harbored a pneumococcus Type $X$ in his pharynx on March 1 , and a pneumococcus Type XXII was obtained on March 14 . He remained well, however, until March 28 when he was admitted to the 
hospital a few hours after the onset of a bronchopneumonia. Pneumococcus Type XXII was again isolated by throat culture on March 29 . W.'s blood serum of March 29 contained no agglutinins or protection against pneumococcus Type $\mathrm{V}$ but microscopic agglutinins for pneumococcus Type XXII were present. A throat culture on April 16 showed only pneumococcus Type VI.

Pa. P., age 2 years, became ill on the same day as D. and W. and was admitted to the hospital on March 28. She had a fever of $102^{\circ}$ for two days and was thought clinically to have a bronchopneumonia. A pneumococcus Type XXII was obtained from $\mathrm{Pa}$. by throat swab. On March 31 she developed an acute otitis media; the ear drum was incised and a culture of the pus on April 1 yielded a pure growth of pneumococcus Type XXII. Her blood serum of March 29 contained no agglutinins for pneumococci Types $\mathrm{V}$ and XXII and no protection for Type V.

H. P., a daughter of 9 years, was a carrier of pneumococcus Type $\mathrm{V}$ on March 1. On March 4 she had microscopic agglutinins and protection for pneumococcus Type V, and also her serum on that date had microscopic agglutinins for Type XXII pneumococcus though a Type XXII was first obtained from H.'s throat on March 14. $H$. became ill on March 17 and was admitted to the hospital on the day of onset with an acute follicular tonsillitis. Throat cultures on March 17 contained a hemolytic streptococcus and a pneumoçoccus Type XXII. Her blood serum on March 17 showed agglutinins for pneumococci Types $\mathrm{V}$ and XXII and protection against Type V. A pneumococcus Type XXII was present in her throat on April 16.

The infant son, R. P., 11/2 months old, was admitted to the hospital with a mild infection on April 1 but no pneumococci were obtained from his throat culture.

There were five remaining members of family $P$. who were not admitted to the hospital. Three throat cultures were made on the mother, Mo. P., but pneumococci were obtained only once, namely a Type $V$ on March 14. The mother's blood had agglutinins and protection for pneumococcus Type V on March 14 but contained no agglutinins against Type XXII. A second blood from Mo. was studied on March 25, at which time the titer of the protective antibodies for pneumococcus Type $\mathrm{V}$ was found to have increased but there were no agglutinins for pneumococci Types V and XXII. The mother throughout the entire period of study was free of respiratory infection.

The grandmother, G. O., who lived temporarily in the same house, had a mild sore throat from February 21 to February 28 but was not confined to bed. On February 28 and again on March 14 a Streptococcus viridans, but no pneumococci, was isolated by throat culture. Her blood serum of March 14 contained no agglutinins for pneumococci Types $\mathrm{V}$ and XXII and no protective antibodies for Type $\mathrm{V}$.

J. P., aged 12 years, remained well. Her throat culture on February 26 yielded a pneumococcus Type V. On March 3 there were agglutinins and protective anti- bodies for pneumococcus Type $\mathrm{V}$ in her blood serum but no agglutinins for Type XXII. The throat culture of March 14 showed pneumococci Type XXII, on March 26 no pneumococci were isolated but on April 16 a pneumococcus Type XXII was again found. The blood serum of March 26 contained no agglutinins for pneumococci Types V and XXII but the protection for Type $\mathrm{V}$ had increased over its previous level.

F. P., age 11, who remained entirely free of respiratory infections, was the first member of the family from whom a pneumococcus Type XXII was obtained. On March 4 his throat culture showed pneumococcus Type XXII and his blood serum of that date had Type XXII agglutinins in a titer of $1: 64$ but contained neither agglutinins nor protective antibodies for pneumococcus Type V. On March 14 both Type V and Type XXII pneumococci were present in his throat cultures and agglutinins were demonstrable in his blood serum of March 14. Between March 4 and March 14, moreover, he had developed a protective titer of 5000 lethal doses per cc. for pneumococcus Type V. The throat culture of April 16 contained only pneumococci of Type XXIII, bui not Type $\mathrm{V}$ or XXII.

Ma. P., 15, had a slight coryza and cough from February 14 to February 28 but was not ill enough to go to bed. On March 1 culture of her throat showed pneumococci Types V and VI. On March 14 a pneumococcus Type $\mathrm{V}$ was obtained and on April 16 no pneumococci were grown on culture. Blood serum of March 2 and of March 14 contained no agglutinins for pneumococci Types V, VI and XXII and no protective antibodies for Type V.

After the finding of a pneumococcus Type XXII in certain members of Family P. apparently as the etiological agent of their disease, the original blood serums of B. and Pe. were tested for the presence of Type XXII agglutinins. The serums of $B$. of February 25 and March 14 were negative but that of March 3 possessed a titer of 1:4. These agglutinins could not be demonstrated in the serum of March 14. Opportunity for further throat cultures on B. was not available. Pe.'s blood serum contained no Type XXII agglutinins on February 26 but on March 4 and March 14 they were demonstrated in low titer. A throat culture of $\mathrm{Pe}$. on April 16 showed a pneumococcus Type XXII.

Summary. Family P. presents a complicated double epidemic of infections, pneumococci Types $\mathrm{V}$ and XXII. Three members, B., Pe., and D., suffered from pneumonia due to the Type $\mathrm{V}$ pneumococcus. Three members, G., W., and Pa., had bronchopneumonia due to pneumococcus Type XXII and one of these had an otitis media due to pneumococcus Type XXII. One, H., had a follicular tonsillitis during which hemolytic streptococci and some Type XXII pneumococci were cultured from the throat. In the five mem- 
bers of the family who either remained well or who had mild colds, pneumococci were obtained from the throat at different times from all except the grandmother, G. O. Antibodies were demonstrated against pneumococci Types $\mathrm{V}$ and XXII in the individuals who were carriers, with the exception of $\mathrm{Ma}$., though the antibody response was more regular against Type $\mathrm{V}$ than against Type XXII. In one individual, F., who remained well, antibodies against pneumococcus Type V developed after a Type $\mathrm{V}$ pneumococcus was obtained by throat culture. Less clearly the same thing is seen in the case of the mother, though unfortunately an early blood could not be obtained. There were also two instances in which agglutinins for Type XXII apparently developed under observation during convalescence from Type V pneumonia. The Type XXII was cultured from the throat of one of these cases some time later, and, in the other, no further cultures were made. In $H$. P., Type XXII agglutinins were demonstrated first, and this pneumococcus was isolated from the throat ten days later.

Family $H$. Detailed studies were made in group Number 19 (1) which consisted of a brother, J. H., a sister, M. H., and a ward contact all of whom had a rapidly fatal Type $V$ pneumococcus pneumonia with bacteremia. The ward contact, H. C., was an ambulant diabetic patient who had acquired a pneumococcus Type $\mathrm{V}$ pneumonia and bacteremia as a result of exposure to J. H. who was ill on the same medical ward. Throat cultures made on the seven patients in the same rooms with J. H. and H. C., and also on four nurses and two orderlies assigned to that ward, failed to reveal any carriers of pneumococcus Type V. Agglutinins and mouse protective antibodies against pneumococcus Type $\mathrm{V}$ could not be demonstrated in any of the seven patients whose blood serum was studied. Because of the completely negative results in the ward contacts where reasonable precaution was exercised this group is not considered further.

\section{DISCUSSION}

Previous investigations of outbreaks of pneumonia in families, institutions, or communities (1) have been concerned with the incidence and spread of disease-producing pneumococci among cases and their contacts. The Types I and II were the only pneumococci concerned in these epidemics except in the institutional outbreak reported by Schroder and Cooper (4) during which Type $\mathrm{V}$ pneumococci were recovered from 7 of the 9 cases of pneumonia which were " typed." During this epidemic there was a high incidence of colds and bronchitis but these were not studied bacteriologically. Other investigators have observed the occurrence of simple upper respiratory tract infections among contacts of cases of Type I or II pneumonia and have noted further that some of them became carriers of these pneumococci; but, with the exception of Joppich (5), they failed to ascribe to them any etiological relationship. Immunological studies have been made during these epidemics only in isolated cases of pneumonia, and then only for the purpose of confirming the type when the patients were first seen during convalescence and the causative organisms had not been identified previously (6).

The observations here presented confirm the finding that a high percentage of the contacts within the family of cases of pneumococcus pneumonia harbor the homologous type pneumococcus in their pharynx. This was shown to be true not only for Types I and II but also for Type V and for the less common Type XXII. It may further be deduced from the data in these families that even healthy contacts may develop specific antibodies in response to the presence in their pharynx of the types of pneumococci which produced disease in their relatives.

It is difficult to find, in the literature, examples of a definitely demonstrated development of specific antibody resulting from proved contact with virulent bacteria without intervening infection or the exhibition of antigenic material. Even with diphtheria immunity, the observations of GarridoMorales and Mandry (7), though seemingly convincing, have failed to meet the objection that the simple performance of the Schick test may be an effective stimulus to antitoxin production in a person with a "basal immunity" $(8,9)$. On the other hand, many observers have noted the coexistence of virulent organisms and circulating antibody as, for example, Schick negative carriers of virulent diphtheria bacilli $(7,8)$. However, in the case of diphtheria and scarlet 
fever which are the diseases usually studied, a degree of immunity similar to that found in such individuals is normally to be expected in a considerable percentage of the population. With type-specific pneumococci, on the other hand, antibody demonstrable by the agglutination test as here performed, or by the mouse protection test in the case of most virulent strains, is rarely encountered in normal human subjects.

In this paper there are presented examples of the appearance of antibody for homologous types of pneumococci after their appearance in the pharynx. Furthermore, the presence of type-specific antibodies in moderately high titer for the homologous type of pneumococcus in most of the healthy contact carriers of the disease-producing pneumococci, the absence of antibodies for other pneumococcus types in the same individuals, and the failure to demonstrate similar antibodies in other contacts in the same family who did not become carriers of the same type, all add convincing evidence for the antigenicity of the carrier state in the case of the disease-producing pneumococci.

These findings, when considered in conjunction with the known transient character of the specific antibodies found in patients convalescent from infections with pathogenic pneumococci, would seem to indicate that when agglutinins or protective antibodies for specific pneumococcus types are demonstrated in the serum of an apparently healthy individual, they may have arisen as a result of previous infection or of a carrier state arising out of contact with the same or related type of pneumococcus.

The absence of demonstrable antibodies for most of the types of pneumococci found in the normal pharynx may then be the result of, 1 - the long duration of the contact and, hence, the disappearance of the demonstrated antibody, or 2the low antigenicity of those particular types, or 3 -the poor antigenic reaction on the part of the carrier.

How far the antibodies resulting from the carrier state render the individual less susceptible to pneumonia or to other serious pneumococcic infections can not be answered by the data at hand. Those infections which developed under our observation were due to organisms other than the one for which immunity had been previously demonstrated.

\section{SUMMARY AND CONCLUSIONS}

Bacteriological studies made on all the members of the household and of some other contacts in five families in which multiple cases of pneumococcus infection were observed revealed a high incidence of carriers of the type of pneumococcus responsible for the infection in the relatives. Serological studies of the carriers and non-carriers showed that homologous type-specific antibodies may develop in a large percentage of healthy contact carriers of disease-producing pneumococci.

\section{BIBLIOGRAPHY}

1. Tilghman, R. C., and Finland, M., Pneumococcic infections in families. J. Clin. Invest., 1936, 15, 493. (The bibliography in this paper contains most of the recent relevant studies.)

2. Finland, M., The significance of mixed infections in pneumococcic pneumonia. J. A. M. A., 1934, 103, 1681.

3. Finland, M., and Winkler, A. W., Antibody response to infections with Type II and the related Type V pneumococcus. J. Clin. Invest., 1934, 13, 97.

4. Schroder, M. C., and Cooper, G., An epidemic of colds, bronchitis and pneumonia due to Type V pneumococci. J. Infect. Dis., 1930, 46, 384.

5. Joppich, G., Uber eine Endemie mit Pneumokokken vom Typus I. Klin. Wchnschr., 1934, 13, 661.

6. Wallbruch, E., Die Lobäre Pneumonie als epidemisch auftretende Erkrankung. Ztschr. f. Hyg., 1935, $117,92$.

7. Garrido-Morales, E., and Mandry, O. Costa, Mechanism of natural immunity to diphtheria. Preliminary report of experiments in Porto Rico. Am. J. Hyg., 1931, 14, 89.

8. Harries, E. H. R., Immunity in the making: Observations based upon some records of Schick and Dick Tests. Proc. Roy. Soc. Med. (Sect. Epid. and State Med.), 1927-28, 21, 197.

9. O'Brien, R. A., Immunity produced by the Schick test. J. Path. and Bact. (Proc.), 1926, 29, 320. 